\title{
Lansoprazole - Induce Black Hairy Tongue- A Case Report
}

\author{
Aryal E', Rajbhandari $\mathbf{M}^{2}$, Bhattarai $\mathbf{S}^{3}$
}

${ }^{1}$ Assistant Professor; ${ }^{3}$ Associate Professor, Department of Dermatology, Venereology and Leprosy, Kathmandu Medical College; ${ }^{2}$ Assistant Professor, Department of Dermatology, Sikkim Manipal Teaching Hospital.

\author{
Address for correspondence
}

Dr. Eliz Aryal

Assistant Professor

\begin{abstract}
Lansoprazole induced black hairy tongue has been rarely reported. The purpose of this paper is to report a case of lansoprazole induce black hairy tongue and review the literature. A 75 year man from eastern part of Kathmandu presented with black hairy fine growth from tongue along with discomfort, burning and halitosis from oral cavity after taking lansoprazole for acute peptic disease(APD) from over the counter and after discontinuation of lansoprazole, black hairy tongue was resolving. Clinically and histopathologically: lansoprazole induced black hairy tongue was confirmed. Black hairy tongue is characterized by abnormal hypertrophy and elongation of filliform papillae.. Lansoprazole is a proton-pump inhibitor (PPI) with a racemic 1:1 mixture of the enantiomers dexlansoprazole which inhibits the stomach's production of gastric acids.
\end{abstract}

Key words: lansoprazole, induce black hairy tongue

\section{Introduction}

D iscoloration of tongue and oral mucosa is a reaction pattern of endogenous and exogenous substances. Proton pump inhibitors (PPI) are widely used as a treatment for peptic ulcer disease and prophylaxis for drug induced gastric ulcer and along with oral steroid, which alter both gastric acid and $\mathrm{pH}$ of oral cavity and gastrointestinal tract which lead to change color of tongue. ${ }^{1}$

Linguavillosa Nigra (LN) also known as Black Hairy tongue $(\mathrm{BHT})$ is painless, benign hairy growth on dorsum surface of tongue; due to defective desquamation and reactive hypertrophy of filiform papillae of the tongue. ${ }^{2}$ It is also known as Keratomycosis Linguae, Melanotrichia, Linguavillosa nigra and Hyperkeratosis of tongue. ${ }^{3}$ It was first described by Lusitanus in 1557 as hair on tongue which can regrow even after being removed. 2,3 Its etiology and pathophysiology have not been fully elucidated, but is mostly present with chronic smoking, alcohol use, poor oral hygiene and certain medications like antibiotics, linezolid and anti cancer drug. The purpose of this article is to present a case of lansoprazole induced Black Hairy tongue (BHT), which has been rarely reported till date.

\section{Case Presentation}

A healthy 75 year old male from eastern part of Kathmandu presented to dermatology OPD with chief complaints of burning sensation, discomfort and bad breath from oral cavity for 8 weeks. He, smoker for last 20 years, had abdominal discomfort along with heartburn and bloating since last 2 years. He had been taking lansoprazole, on and off, for last the 12 months and since the last 2 months, he has been taking it regularly from local chemist as over the counter (OTC) drug without consulting the physician. He was of normal built with vitals within normal limits. On intra oral examination, there was poor oral hygiene with stains on teeth with superficial black to brown hairy like growth on dorsum of tongue that appeared as an elongation of filliform papillae almost $3 \mathrm{~mm}$ in growth (fig:1). There was no history of pain, itching and bleeding from oral cavity.

Culture of the dorsal surface of tongue was negative for bacterial and fungal outgrowth after 48 and 72 hours. Routine blood investigation were within normal limit along with negative HIV test. A $4 \mathrm{~mm}$ punch biopsy was taken under sterile condition, with consent from patient, from the dorsum of tongue. Histopathological study showed elongation and hyperparakeratosis of the filiform papillae (fig:2). 
Clinically and histopathologically diagnosis of BHT was made. Patients was advised to stop lansoprazole along with cessation of smoking along with gentle tongue debridement with soft toothbrush and was referred to dental department for assessment and management of oral cavity. On follow up after 8 weeks (fig:3), there was resolving $\mathrm{BHT}$ with almost normal texture. Hence final diagnosis was Black Hairy Tongue (Clinically: Lansoprazole induced).

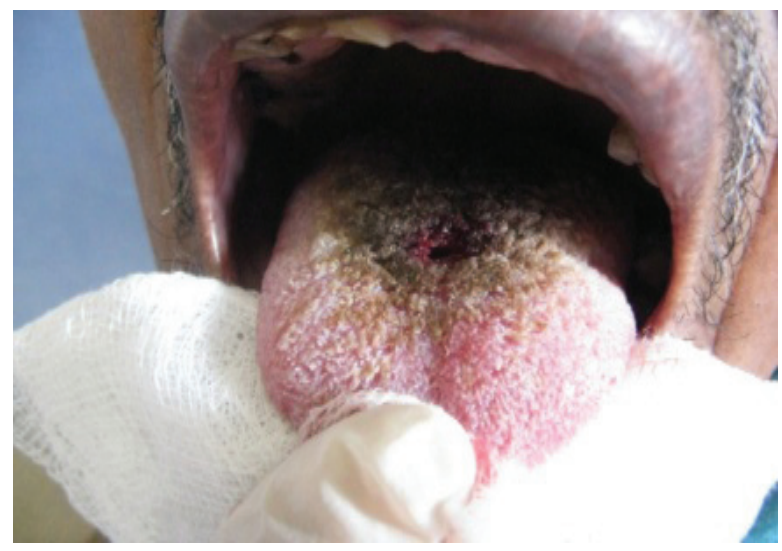

Figure 1: BHT on dorsum of tongue with $4 \mathrm{~mm}$ punch biopsy

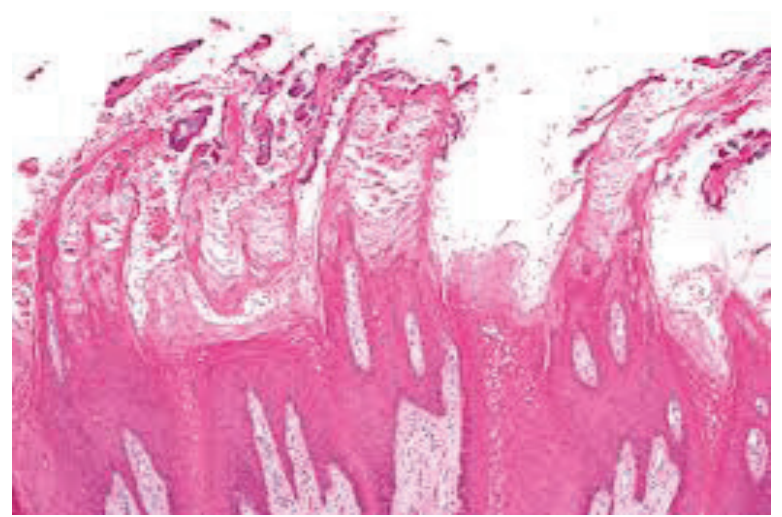

Figure 2: Elongated and hyper-para-keratosis of filiform papillae

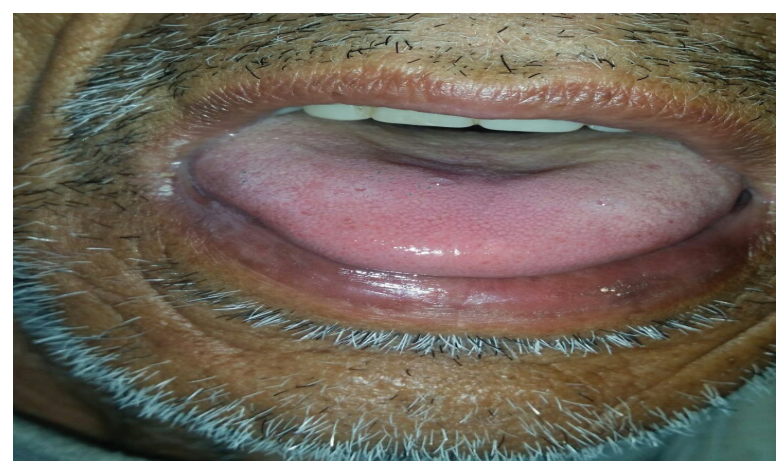

Figure 3: BHT after 8 weeks of discontinuation of lansaprazole

\section{Discussion}

$\mathrm{BHT}$ has been reported in patient with poor oral hygiene and chronic smoker. Our patient had been smoking since last 20 years and though we advised him to stop smoking, he continued with decreased frequency of smoking. This might have helped in improving his condition. A study in Turkish dental patients showed causal smoker poses slightly increased risk of having BHT compared to non smoker and male subjects had greater prevalence of BHT. ${ }^{4}$ Excessive coffee, black tea, poor oral hygiene and radiation therapy of head and neck region can trigger $\mathrm{BHT}^{4}{ }^{4}$ Dry mouth due to radiation therapy can cause severe xerostomia and even many drugs like anticholonergic, anti depressant and anti hypertensive drugs can further aggravate xerostomia which lead to alter $\mathrm{pH}$ of oral cavity and lead to defective desquamation and prevent normal debridement leading to accumulation of keratinized layer and hypertrophy of filiform papillae into hair like growth. ${ }^{5}$ Similarly a case of BHT has been reported in patient with trigeminal neuralgia with decreased tongue movement and mastication ultimately hindering desquamation of keratinized filiform papillae..$^{5,6}$ Use of systemic and local medication has been implicated in development of BHT.

Antibiotic including penicillin, erythromycin, doxycycline and neomycin are mostly associated with this disorder. ${ }^{5}$ Linezolid induced $\mathrm{BHT}$, which resolved spontaneously after stopping it, has been reported. ${ }^{7,8}$ Local and systemic antibiotic significantly alter oral flora, thus potentially predisposing the patient to develop BHT. This alteration of oral flora predispose to trapping of foreign material and stimulate local microbial overgrowth that lead to color change with delayed desquamation of cells in central column of filiform papillae and marked retention of secondary papillary cells that express hair type keratins. ${ }^{9}$

Many capsule and tablet contain red, black, yellow ferric oxide as a colorant which accumulates as debris with overgrowth of bacteria and yeasts which lead to synthesis of porphyrin producing chromogenic organisms resulting in $\mathrm{BHT}^{5}$

Our patient was on lansoprazole since last one year irregularly but regularly since last 2 months. He noticed black hairy growth on tongue 6 weeks after starting lansoprazole which was diagnosed clinically and microscopically as Black Hairy Tounge (BHT). He was advised to stop lansoprazole completely with maintaining proper oral hygiene with regular follow up. We noticed, improvement in tongue after 8 weeks of discountinuation of lansoprazole. This evidence 
helped to make our diagnosis as" lansoprazole induced black hairy tongue".

PPI are widely used along with oral steroid as a prophylaxis and as treatment of peptic ulcer. PPI inhibit the hydrogen-potassium adenosine triphosphatase enzyme system, which is the final stage of production of gastric acid in stomach. ${ }^{10}$ The decrease or change of gastric acid production by PPI lead to increase $\mathrm{pH}$ in stomach and oral saliva leading alteration of oral microbial growth and overgrowth of chromogene micro-organism and hence tongue discoloration. ${ }^{11}$ Six cases of BHT in association of PPI (omeprazole, pantoprazole) with positive rechallenge in one patients was reported in database of Netherlands Pharmacoviglance Centre Lab and WHO on July 14, 2009. Similarly, in a case report by Sakallioglu Ohas, six years girl developed BHT after second week of Helicobacter pylori regimen containing antiboiotic along with lansoprazole and it resolved after one week cessation of drugs ${ }^{12}$. In dermatological practice we use oral steroid along with PPI as one of the main line of treatment. So we need to be even more aware about the possible side effecst of not only oral steroid but also of PPI.

\section{Conclusion}

BHT is asymptomatic, but can cause serious psychological impact on patient and need to manage with proper education of oral hygiene maintenance. Any drug, even commonly used, may cause BHT and should be documented and reported, so that in coming future we can have more evidence based database.

\section{References}

1. Eckley CA, Costa HO. Comparative study of salivary $\mathrm{pH}$ and volume in adults with chronic laryngopharyngitis by gastroesophageal reflux disease before and after treatment. Braz J Otorhinolaryngol 2006; 72(1): 55-60. https:// doi.org/10.1016/S1808-8694(15)30035-5

2. Shetty SM, Shetty R. Hairy Tongue (L.N.) A case report. International Journal of Dental Clinics 2011; 3(3): 75-769.

3. Vano- Lalvan S, Jaen P. Black Hairy Tongue. Cleveland Clinic Journal of Medicine . 2008; 75(12): 847-48. https://doi.org/10.3949/ ccjm.75a.08023

4. Avcu N, Kanli A .The prevalence of tongue lesion in 5150 Turkish dental outpatients. Oral Dis 2003; 9: 188-95. https://doi.org/10.1034/ j.1601-0825.2003.02933.x

5. Thompson DF, Kessler TL. Drug-induced Black hairy tongue. Pharmacotherapy 2010; 30: 585593. https://doi.org/10.1592/phco.30.6.585

6. Cheshire WP. Unilateral black hairy tongue in trigeminal neuralgia. Headache 2004; 44: 908-910. https://doi.org/10.1111/j.15264610.2004.04173.x

7. Refaat.M, Hyle E, Malhotra R, SeidmanD, Dey B. Linozolide induce lingua villosa nigra. AM J

MED.2008;121:e1. https://doi.org/10.1016/j. amjmed.2008.02.023

8. Ilkay B, Efsan Y, Mehmet D: Black hairy tongue: a rare side effect of lineolide. Our dermatol online 2012; 3(2): 136-137. https://doi.org/ 10.7241/ourd.20122.30

9. Manabe M, Lim HW, Winzer M, Loomis CA. Architectural organization of filiform papillae in normal and black hairy tongue epithelium: dissection of differentiation pathways in a complex human epithelium according to their patterns of keratin expression. Arch Dermatol. 1999; 135: 177-181. https://doi. org/10.1001/archderm.135.2.177

10. Vautier G. Scott BB. A one-week quadruple eradication regimen for Helicobacter pylori in routine clinical practive. Aliment Pharmacol Ther 1997; 11(1): 107-8. https://doi. org/10.1046/j.1365-2036.1997.87259000.x

11. Bradshaw DJ, Marsh PD. Analysis of pH-driven disruption of oral microbial communities in vitro. Caries Res 1998; 32(6): 456-62. https:// doi.org/10.1159/000016487

12. Sakallioglu O. Black tongue due to lansoprazole plus metronidazole. Indian Pediatr. 2014; 51(9): 763. https://doi.org/10.1007/s13312014-0500-2 